Revised version to appear in Shigeru Miyagawa and Mamoru Saito, eds., Handbook of Japanese Linguistics, Oxford University Press.

\title{
Lexical Classes in Phonology
}

\author{
August 2006 \\ Junko Ito and Armin Mester \\ UC Santa Cruz
}

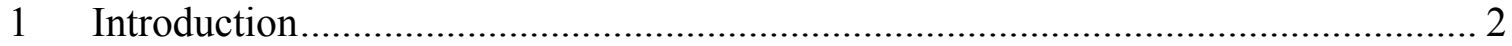

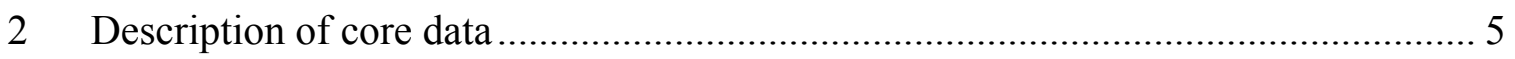

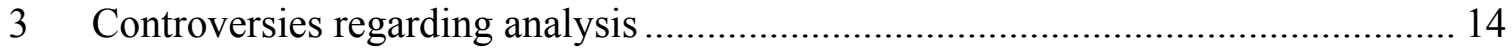

3.1 Indexed faithfulness vs. co-grammars .................................................. 14

3.2 Indexed faithfulness vs. indexed markedness ......................................... 16

3.3 Indexed faithfulness and default $\mathrm{M} \gg \mathrm{F}$ ranking ......................................... 19

3.4 Indexed faithfulness and restrictiveness .............................................. 20

3.5 Loanword adaptation and perceptual assimilation................................... 20

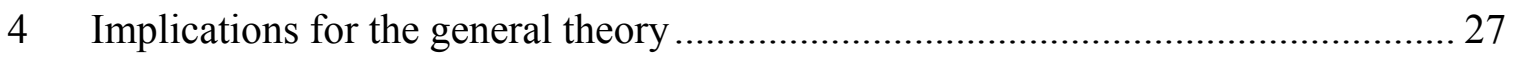

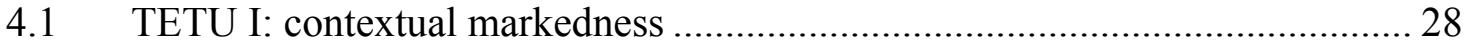

4.2 TETU II: Allomorphy and faithfulness neutralization................................ 30

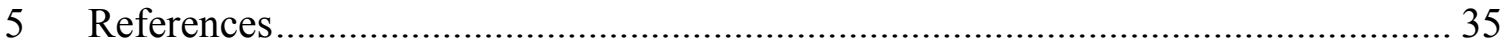




\section{Introduction}

Linguistic descriptions of natural languages routinely face the necessity to draw distinctions between different lexical classes--such as Latinate vs. native roots in English, to which affixes like noun-forming -ation are sensitive ([lat vari]ation, but *[nat buri]ation, etc; see Ito and Mester 1995b:818 for relevant examples from a variety of different language). Details vary from language to language, but the basic observation is the same: Not all morphemes participate in the major morphological and phonological processes to the same degree.

The status of such morpheme classes, or lexical strata, in the synchronic grammar has long been a controversial issue in linguistics, and the Japanese language has played a key role in these discussions, partially because lexical class distinctions are so prominent here, and so clearly visible, even in the writing system. The examples in (1) (from Ito and Mester 2003:122) illustrate the phenomenon with the perhaps most well-known case of this kind in Japanese, where native morphemes undergo a widespread morphophonemic process of compound voicing (rendaku), but non-native morphemes (both Sino-Japanese items and Western loans) do not. 
(1)

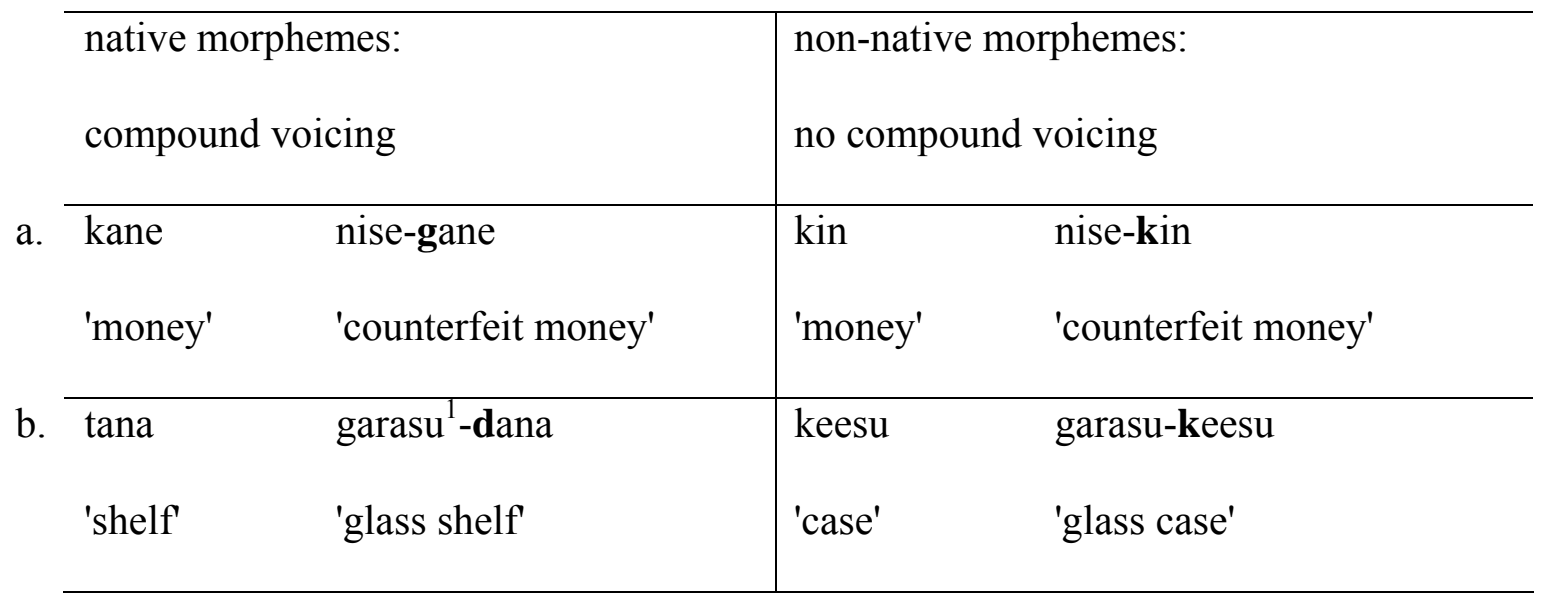

With the shift in phonology from a rule-based derivational framework to a system of ranked and violable constraints that came with the rise of Optimality Theory over the last fifteen years, a new perspective on this topic has developed in recent years, and we would like to take up some of the issues connected with it, some of its theoretical consequences, and its empirical predictions and problems.

Ito and Mester 1995a, with further development in Fukazawa 1998 and Ito and Mester 1999, among others, argued that the distinguishing formal property of lexical strata in an optimality-theoretic grammar is stratum-specific faithfulness ranking, within an otherwise invariant hierarchy of markedness constraints (see Inkelas, Orgun and Zoll 1997, Pater 2000, and Anttila 2002 for interesting alternative proposals sharing the same basic approach). This results in a containment hierarchy of inventories of the kind depicted in (2): The more markedness constraints are active on a given stratum (by

\footnotetext{
${ }^{1}$ Here and throughout, we use $[\mathrm{u}]$ as a convenient broad transcription for what is in many (though not all) varieties of Japanese realized as unrounded [u]. Similarly, we use [f] for bilabial $[\phi]$.
} 
dominating stratum-specific faithfulness), the more structures are ruled out, and the smaller the inventory associated with the stratum.

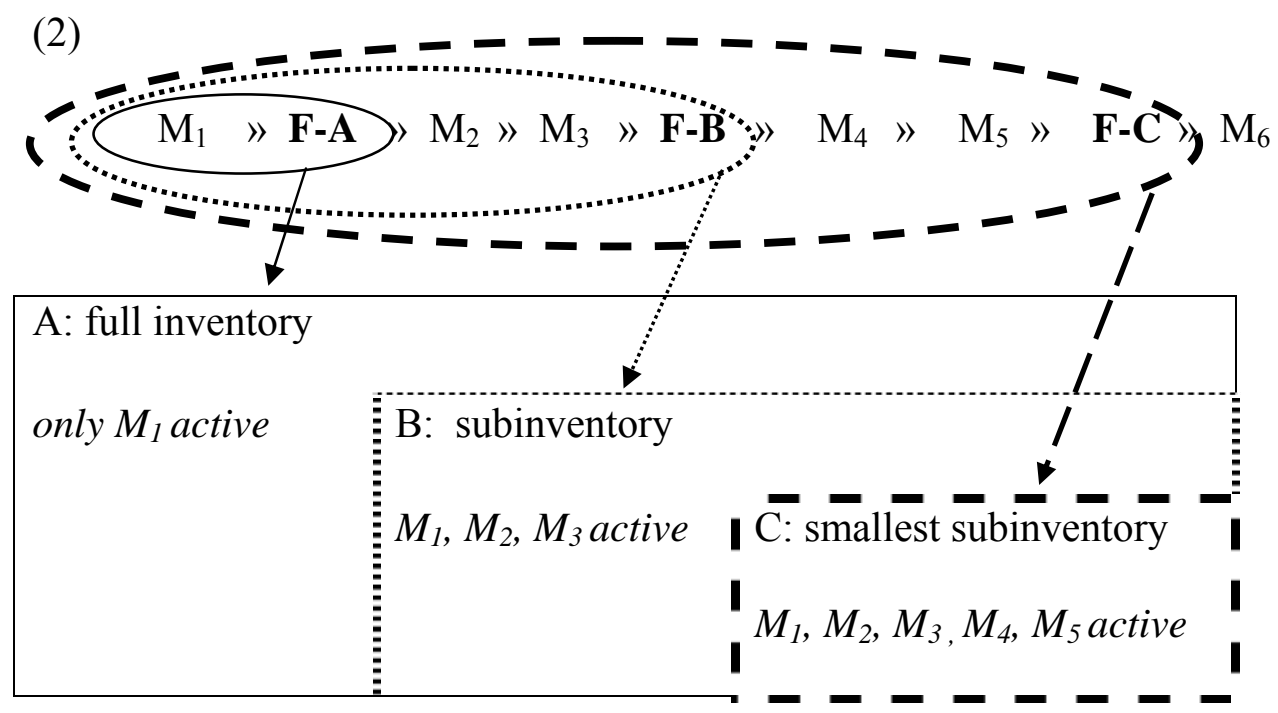

The empirical interest of nested inventory structures as in (2) lies in the fact that they seem to provide good models for the vocabularies of natural languages, which can in many cases be shown to be organized in this way. This is shown in (3), which summarizes some of our main findings for the lexicon of Japanese: The Yamato (native) inventory is the most restrictive, observing all three constraints relating to voicing; SinoJapanese items are exempt from the postnasal voicing requirement and fall into two subcategories, depending on whether or not they observe compound voicing; and the Foreign vocabulary is exempt from all three constraints. 
(3)

\begin{tabular}{|c|c|c|c|c|c|}
\hline & Foreign & $\begin{array}{l}\text { Sino- } \\
\text { Japanese } \\
\text { A }\end{array}$ & $\begin{array}{l}\text { Sino- } \\
\text { Japanese } \\
\text { B }\end{array}$ & Yamato & \\
\hline a. OCP(VOI) & no & yes & yes & yes & $\begin{array}{l}\text { observes multiple } \\
\text { obstruent voicing } \\
\text { ban }\end{array}$ \\
\hline $\begin{array}{l}\text { b. REALIZE- } \\
\text { M(ORPHEME) }\end{array}$ & no & no & yes & yes & $\begin{array}{l}\text { here: realizes } \\
\text { compound voicing } \\
\text { morpheme }\end{array}$ \\
\hline c. No-NÇ & no & no & no & yes & $\begin{array}{l}\text { observes postnasal } \\
\text { voicing requirement }\end{array}$ \\
\hline $\begin{array}{l}\text { Containment } \\
\text { relations } \\
\text { between the } \\
\text { inventories: }\end{array}$ & & & & 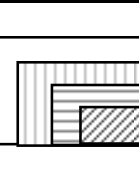 & \\
\hline
\end{tabular}

\section{Description of core data}

Previewing our main results, grammars that give rise to such nested inventory structures have a stratally differentiated faithfulness component of the kind given in (4) for Japanese, where we write "F" for foreign, "SJ" for Sino-Japanese and "CSJ" for "Common Sino-Japanese", and Y for "Yamato" or "native".

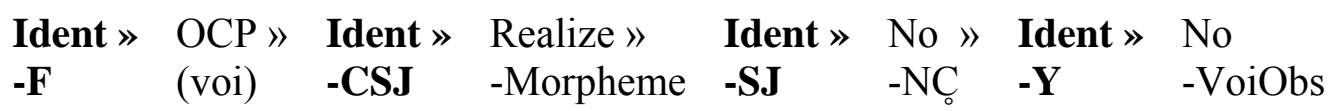


That $\mathrm{OCP}(\mathrm{VOI})$ is active on Y-morphemes and SJ-morphemes is shown in $(5 \mathrm{a}, \mathrm{b}){ }^{2}$ whereas F-morphemes are free to have two voiced obstruents $(5 \mathrm{c})$.

$\begin{array}{llll}\text { a. } & \text { tako } & \text { 'octopus' } & \text { *dago } \\ \text { toge } & \text { 'splinter' } & \text { *doge } \\ \text { geta } & \text { 'clog' } & \text { *geda } \\ \text { b. } & \text { getu } & \text { 'month' } & \text { *gedzu } \\ \text { geki } & \text { 'theater' } & \text { *gegi } \\ \text { doku } & \text { 'poison' } & \text { *dogu } \\ & \text { butu } & \text { 'thing' } & \text { *budzu } \\ \text { c. } & \text { daburu } & \text { 'double' } & \\ & \text { baggu } & \text { 'bag' } \\ & \text { bebii } & \text { 'baby' } \\ & \text { baabekyuu } & \text { 'barbecue' }\end{array}$

While $(5 \mathrm{a}, \mathrm{b})$ suggest that markedness is active--schematically: MARK»FAITH--this is contradicted by (5c). Stratal faithfulness means that, instead of a wholescale deactivation of markedness (FAITH»MARK), we find only partial deactivation: FAITH- $\alpha$ » MARK » FAITH, with undifferentiated faithfulness remaining in its dominated position. This crucially requires the existence of a lexical class $\alpha$ (here, foreign items) that is

\footnotetext{
${ }^{2} \mathrm{SJ}$-morphemes in fact observe an even stronger requirement: $\mathrm{C} 2$ cannot be a voiced obstruent
} 
recognizable for the learner by a combination of properties, including both phonotactics and morpheme combinatorics (native stems mostly combining with native suffixes, etc.) The extent to which the behavior of novel forms can be predicted on the basis of their shape alone, is unclear (see Pierrehumbert 2006 for a case of statistical predictability involving velar softening in English; see also Pater 2005 for an explicit procedure for constructing such indexed constraints on the basis of universal constraints in the course of learning). For the present case, this means high-ranking faithfulness IDENT-F for Fitems dominates $\mathrm{OCP}(\mathrm{VOI})$ :

(6) Ident-F » $\mathrm{OCP}($ voi) » Ident

This allows for double voiced obstruency in F-indexed items such as daburu 'double', but for an hypothetical input / dogu/ not indexed for F (and ultimately, within the fully developed stratal system, indexed for SJ or Y) and hence subject to general faithfulness, the grammar takes corrective action and outputs a less marked structure (either doku or togu, depending on the verdict of other constraints).

(7) a. daburu 'double'

\begin{tabular}{|l|l|l|l|}
\hline$/$ daburu/F & Ident-F & OCP(voi) & Ident \\
\hline daburu & & $*$ & \\
\hline taburu & $* !$ & & $*$ \\
\hline
\end{tabular}


b. Hypothetical input /dogu/

\begin{tabular}{|l|l|l|l|}
\hline$/ \operatorname{dogu} /$ Y/SJ & Ident-F & OCP(voi) & Ident \\
\hline $\operatorname{dogu}$ & & $* !$ & \\
\hline doku & & & $*$ \\
\hline togu & & & $*$ \\
\hline toku & & & $* * !$ \\
\hline
\end{tabular}

The next constraint to consider is No-NÇ, which militates against sequences consisting of nasals followed by voiceless obstruents. As (8) shows, it is active on Yitems (8a) (NO-NÇ » IDENT--we take Y-items to be associated with un-indexed IOFaithfulness, unless there is a specific reason to introduce a specific IDENT-Y), ${ }^{3}$ but not on SJ- or F-items $(8 b, c)$ (IDENT-F, IDENT-SJ » NO-NÇ).
a. tombo
'dragonfly'
*tompo
kangae
'thought'
*kankae
cf. also alternations such as

$$
\text { /yom }+ \text { ta/ } \rightarrow \text { [yonda }] \quad \text { read'-PAST }
$$$$
\text { /yom }+ \text { te/ } \rightarrow \text { [yonde] } \quad \text { 'read'-GERUND }
$$

\footnotetext{
${ }^{3}$ But see Kawahara, Nishimura and Ono 2003 for arguments that faithfulness constraints for Sino-Japanese are ranked lower than those for Yamato.
} 


$\begin{array}{ll}\text { /yom+tara/ } \rightarrow \text { [yondara] } & \text { 'read'-CONDITIONAL } \\ \text { /yom+tari/ } \rightarrow \text { [yondari] } & \text { 'read'-NONEXHAUSTIVE LISTING } \\ \text { gen+ki } & \text { 'health(y)' } \\ \text { kan+koo } & \text { 'sightseeing' } \\ \text { den+pa } & \text { 'electric wave' } \\ \text { san+po } & \text { 'walk' } \\ \text { sen+soo } & \text { 'war' } \\ \text { han+too } & \text { 'peninsula' } \\ \text { panku } & \text { 'puncture, flat tire' } \\ \text { torankiraizaa } & \text { 'tranquillizer' } \\ \text { syanpuu } & \text { 'shampoo' } \\ \text { konpyuutaa } & \text { 'computer' } \\ \text { konsaato } & \text { 'concert' } \\ \text { sentaa } & \text { 'center' } \\ \text { bentyaa } & \text { 'venture (firm)' }\end{array}$

This means that a new species of stratified faithfulness, IDENT-SJ, has emerged out of general IDENT and lodges above No-NC, preserving the relations encoded in (6), i.e., beneath OCP(VOI) (different from IDENT-F). The new subgrammar obtained is (9), where the box encloses the newly added constraints.

(9) Ident-F » OCP(voi) » Ident-SJ » No-NC $»$ Ident 
The tableaux in (10) illustrate how this grammar segregates Y-, SJ-, and F-items, respectively.

a. sinde 'die-GERUND'

\begin{tabular}{|l|l|l|l|l|}
\hline$/$ sin-te/Y & Ident-F & Ident-SJ & No-NC & Ident \\
\hline sinte & & & $* !$ & \\
\hline sinde & & & & $*$ \\
\hline
\end{tabular}

b. kankoo 'sightseeing'

\begin{tabular}{|l|l|l|l|l|}
\hline$/$ kankoo/sJ & Ident-F & Ident-SJ & No-NC & Ident \\
\hline kankoo & & & $*$ & \\
\hline kangoo & & $* !$ & & $*$ \\
\hline
\end{tabular}

c. sentaa 'center'

\begin{tabular}{|l|l|l|l|l|}
\hline$/$ sentaa/F & Ident-F & Ident-SJ & No-NC & Ident \\
\hline sentaa & & & $*$ & \\
\hline sendaa & $* !$ & & & $*$ \\
\hline
\end{tabular}


It is often seen as a problem for lexical strata that their boundaries are fuzzy:

Nativization of loanwords is a gradual affair, making it difficult to draw a clear line in the lexicon separating native from non-native items. In Japanese, a well-known problem of this kind arises in connection with the distribution of compound voicing, usually considered to be restricted to Yamato items. We will here assume a basic analysis developed elsewhere (Ito and Mester 1986, 2003) that understands compound voicing as the manifestation of a grammatical linking morpheme (/ori $+\mathrm{R}[\mathrm{voi}]+\mathrm{kami} / \rightarrow$ [origami] 'paper folding', etc.) whose realization is governed by the constraint REALIZEM(ORPHEME). Lack of compound voicing in SJ-items means that REALIZE-M is dominated by IDENT-SJ , as in (11), preventing a change in the voicing feature. Illustrative examples appear in (12).

(11) Ident-F » OCP(voi) »Ident-SJ $\leadsto$ Realize-M, No-NC $\} »$ Ident

(12) a. sinbun haitatu SJ 'newspaper delivery'

\begin{tabular}{|r|l|l|l|l|}
\hline$/$ sinbun +R+ haitatu/sJ & OCP(voi) & Ident-SJ & Realize-M & Ident \\
\hline sinbun haitatu & & & $*$ & \\
\hline sinbun baitatu & & $* !$ & & $*$ \\
\hline
\end{tabular}

b. ike bana y 'flower arrangement'

\begin{tabular}{|r|l|l|l|l|}
\hline$/$ ike $+\mathrm{R}+$ hana/Y & OCP(voi) & Ident-SJ & Realize-M & Ident \\
\hline ike hana & & & $* !$ & \\
\hline ike bana & & & & $*$ \\
\hline
\end{tabular}


The overall grammar developed so far has the ranking shown in (13).

\begin{tabular}{|c|c|c|}
\hline Ident » & $\begin{array}{l}\text { OCP } \text { (voi) }\end{array}$ & $\begin{array}{l}\text { Ident » } \\
\text {-SJ }\end{array}$ \\
\hline
\end{tabular}

That we are dealing here with aspects of the synchronic grammar as acquired by contemporary speakers, and not just with quasi-sedimentary layers of history visible in the vocabulary of the language, is shown by numerous cases where lexical class membership diverges from etymological origin. Some examples are given in (14). Takayama (1999) argues that such native look-alikes are phonotactically indistinguishable from Y-morphemes, and have in fact changed stratal membership.

(14) Non-native undergoers of compound voicing

a. Older Western loans: iroha garuta 'syllabary playing cards' (karuta), ama gappa 'rain cape' (kappa)

b. Loans from Chinese: no giku 'wild chrysanthemum' (kiku), tya gasi 'tea sweets' (kasi)

c. Recent Western loans: take zukii ${ }^{4}$ 'bamboo skis' (sukii)

\footnotetext{
${ }^{4}$ A Kanazawa dialect form, according to the NHK series Furusato Nihon-no kotoba (2000-01)
} 
But lexical distinctions are more fine-grained than wholescale nativization, and it is an important test for any model whether it provides enough flexibility to draw all the necessary distinctions. The grammar in (13) makes a clear prediction: A further stratal distinction could in principle be made by faithfulness ranking between the (so far unranked) constraints REALIZE-MORPHEME and NO-NÇ,

It is therefore of great interest that this is precisely what we find: A class of SinoJapanese items in everyday use (some examples are given in (15)) that have become nativized enough to undergo compound voicing, but are still special in other respects, as seen by the fact that they can fail to conform to No-NC.

\begin{tabular}{|c|c|c|c|}
\hline kenka & 'quarrel' & oyako-genka & 'parent-child quarrel' \\
\hline $\operatorname{tansu}$ & 'drawers' & yoohuku-dansu & 'drawers for clothes' \\
\hline kaisya & 'company' & zidoosya-gaisya & 'car company' \\
\hline hootyoo & 'carver' & deba-bootyoo & 'pointed carver' \\
\hline toohu & 'tofu' & yu-doohu & 'hot tofu' \\
\hline husoku & 'lack' & ne-busoku & 'lack of sleep' \\
\hline kotatu & 'table warmer' & denki-gotatu & 'electric table warmer \\
\hline
\end{tabular}

Takayama (1999) argues that these items belong to a separate substratum, here referred to as "Common Sino-Japanese" ("CSJ"). The final version of the grammar is given in (16), where faithfulness is fully distributed over the markedness hierarchy. 


\begin{tabular}{|c|c|c|c|c|c|c|c|c|}
\hline $\begin{array}{l}\text { Ident } \gg \\
-F\end{array}$ & $\begin{array}{l}\text { OCP » } \\
\text { (voi) }\end{array}$ & $\begin{array}{l}\text { Ident » } \\
\text {-SJ }\end{array}$ & $\begin{array}{l}\text { Realize » } \\
-\mathbf{M}\end{array}$ & $\begin{array}{l}\text { Ident » } \\
\text {-CSJ }\end{array}$ & $\begin{array}{l}\text { No } \\
\text {-NC }\end{array}$ & & $\begin{array}{l}\text { Ident } \gg \\
-\mathrm{Y}\end{array}$ & $\begin{array}{l}\text { No } \\
\text {-VoiObs }\end{array}$ \\
\hline
\end{tabular}

Partial nativization phenomena and transitional strata therefore provide important support for this model.

\section{Controversies regarding analysis}

Recent work on lexical classes in phonology, spurred, in part, by the detailed analyses and proposals regarding the Japanese lexicon, has led to fresh questions and various types of inquiries. These range from the specific formal implementation within Optimality Theory, to the implications of such a system in the broader arena of linguistic inquiry including psycholinguistic studies, language acquisition and diachronic change. We will here briefly take up some of the issues that have received most attention.

\subsection{Indexed faithfulness vs. co-grammars}

The formal expression of lexical classes by means of indexed faithfulness, motivated in some detail in the previous section, is based on Correspondence Theory (McCarthy and Prince 1995). Lexical strata result from splitting up individual constraints into stratumspecific indexed versions (Fukazawa 1998, Ito and Mester 1999, Ito and Mester 2003, Pater 2000, among others). Besides this correspondence-theoretic version, an alternative 
formal implementation within OT is the 'co-grammar' approach advocated by a number of researchers including Anttila 2002, Inkelas, Orgun and Zoll 1997, and Ito and Mester 1995b. In this view, lexical strata result from a class of slightly different stratum-specific grammars ('co-grammars'), with different constraint rankings of constraints, that collectively form a family of grammars. This is illustrated below for the body of data discussed in the previous section. Instead of a single grammar (see (16)) with multiple indexed faithfulness constraints, there are multiple co-grammars with a single, but differently ranked faithfulness constraint (17).

(17) Multiple co-grammars with a single faithfulness constraint:

\begin{tabular}{|c|c|c|c|}
\hline $\begin{array}{l}\text { Co-grammar } 1 \\
\text { (Yamato) }\end{array}$ & $\begin{array}{l}\text { Co-grammar } 2 \\
\text { (Common } \\
\text { Sino-Japanese) }\end{array}$ & $\begin{array}{l}\text { Co-grammar } 3 \\
\text { (Sino-Japanese) }\end{array}$ & $\begin{array}{l}\text { Co-grammar } 4 \\
\text { (Foreign) } \\
\text { Ident }\end{array}$ \\
\hline OCP(voi) & OCP(voi) & $\begin{array}{c}\text { OCP(voi) } \\
\mid \\
\text { Ident } \\
\mid\end{array}$ & OCP(voi) \\
\hline $\begin{array}{l}\text { Realize- } \\
\text { Morpheme }\end{array}$ & $\begin{array}{c}\text { Realize- } \\
\text { Morpheme } \\
\mid \\
\text { Ident }\end{array}$ & $\begin{array}{l}\text { Realize- } \\
\text { Morpheme }\end{array}$ & $\begin{array}{l}\text { Realize- } \\
\text { Morpheme }\end{array}$ \\
\hline $\begin{array}{c}\text { No-NC } \\
\mid \\
\text { Ident } \\
\mid \\
\text { NoVoicedObs }\end{array}$ & NoVoicedObs & $\left.\right|_{\text {NoVoicedObs }}$ & NoVoicedObs \\
\hline
\end{tabular}

For a co-grammar approach to be a viable alternative to the single-grammar approach, it would be necessary to flesh out the theory in more detail so that questions 
regarding the extent to which co-phonologies differ and how they interact can be answered (for proposals along these lines, see Orgun 1996). Which constraints can be reranked? The co-grammars in (17) only rerank faithfulness constraints (a proposal first made in Ito and Mester 1995b on the basis of other facts in Japanese), but is this a necessity? How are forms composed of morphemes from different strata evaluated? Stratal organization of the lexicon does not mean stratal uniformity of morphological structures. For example, for a compound form like [supootu dayori] 'sports tidings', cogrammar 4 would have to deal with the first member from the Foreign stratum, and cogrammar 1 would have to deal with the second member from the Yamato stratum. Which co-grammar would deal with the accentuation of the entire compound? These are implementation questions that can no doubt be resolved, but it remains true that these complications simply do not arise in the single model grammar.

\subsection{Indexed faithfulness vs. indexed markedness}

On the other hand, close related questions arise in the single grammar model in connection with the concept of indexation itself. In the model presented in the previous section and argued for in more detail in Ito and Mester 2003 and earlier work based on Japanese phonology, indexation of constraints is restricted to faithfulness constraints, but it is an open question whether indexation is also an option for markedness constraints. Should indexation be available to both faithfulness and markedness, or to only one or the other type of constraints? Restrictiveness demands us to consider this question carefully, and to not automatically adopt the most permissive approach without argument. Several researchers have taken the position that it is not always possible to capture all the facts 
with one type or the other. Thus Pater (2000) has argued that both types of indexed constraints are necessary to capture the details of secondary stresses in English (see also Anttila 2002 on Finnish and Anttila and Cho 1998 on English). On the other hand, if indexation is restricted to a certain type of constraint in some way, does the restriction follow from something else in the theory?

Stepping back from the pros and cons that arise from the--real or apparent-descriptive necessities raised by particular phenomena, we focus here on some of the basic implications of a stratal faithfulness approach versus a stratal markedness approach for the overall theory. To take a simple example, consider the well-known palatalization in Japanese of coronal plosives and fricatives before [i], which applies to native and nativized words (mat-i-masu $\rightarrow$ matf-i-masu 'wait, polite present'), but not to recent loanwords (paatii $\rightarrow$ *paat/fii 'party'). The constraints and rankings necessary for the two approaches are given in (18) and (19), using "PAL" as an informal abbreviation for the well-known constraint demanding palatalization of coronals before high front vowels.

(18) Indexed faithfulness:
IDENT-loan
$»$
PAL
$»$
IDENT

(19) Indexed markedness:
PAL-native
»
IDENT

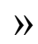
PAL

In the indexed faithfulness approach (18), the general faithfulness constraint IDENT ranked below the markedness constraint PAL ensures palatalization in the (unmarked) 
native items, whereas the special (indexed) faithfulness constraint ranked above PAL prohibits palatalization for the loan items. On the other hand, in the indexed markedness approach (19), the special (indexed) markedness constraint PAL ranked above faithfulness ensures palatalization in native items, whereas the general markedness PAL ranked below faithfulness is unable to enforce palatalization outside of the native stratum. Although both approaches capture this simple palatalization case, some considerations militated against the idea of indexed markedness. (i) Faithfulness constraints have two arguments-an input and an output--, indexation to certain classes of inputs is therefore a natural development. This is not so for markedness constraints, which apply strictly to outputs. (ii) Relativization of markedness to a specific domain raises the possibility of templatic constraints, such as NOCODA/REDUPLICANT, and thereby the specter of pathological backcopying (McCarthy and Prince 1999:258-267), with mouse reduplicated as mou-mou through a ranking such as NOCODA/RED, MAX-BR » MAX-IO » NOCODA (see Ito and Mester 1999:90-91 for a fuller development of points (i) and (ii)). (iii) Indexed markedness constraints resurrects the language-particular processes of rule-based phonology (McCawley 1968, Chomsky and Halle 1968, among others) where "palatalization" is earmarked to apply only to [+native] forms: $\mathrm{t}[+$ native $] \rightarrow \mathrm{t} f / \ldots$ i. Abolishment of language-particular processes is an important achievement of OT, their reintroduction as ranked constraints must raise theoretical concerns. (iv) Indexed faithfulness treats ("native") palatalization before [i] as the general case, contrasting with ("foreign") non-palatalization as the special case. This is just the opposite of the specialgeneral relation with indexed markedness, which singles out palatalization before [i] as the special case. The latter is odd because such palatalization is the unmarked situation, 
universally and in each individual language. Indexed markedness turns this state of affairs on its head.

\subsection{Indexed faithfulness and default M»F ranking}

Stratification is one way of maintaining a version of the low (default, dominated) position of $\mathrm{F}$ even in the face of counterevidence-whenever it is possible to confine the counterevidence within a stratum $\alpha$ whose inhabitants have other things in common. Instead of immediately collapsing in the face of anti-M data (20a), stratification means trying out option (20b).
a. $\mathrm{M} \gg \mathrm{F}$

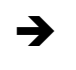
$\mathrm{F} \quad \gg \quad \mathrm{M}$
b. M »
$\mathrm{F}$
$\mathrm{F}-\alpha \quad \gg$
M \
$\mathrm{F}$

This can be seen as an instance of the $\mathrm{M} » \mathrm{~F}$ ranking default (Smolensky 1995), available only when the members of stratum $\alpha$ have several characteristics in common, not just their identical behavior with respect to a single constraint. The latter point should follow from the economy considerations concerning the overall grammar, and forestalls the possibility of pseudo-strata (such as *VOIOBS-observing pick vs.*VOIOBS-violating pig in English). 


\subsection{Indexed faithfulness and restrictiveness}

It is sometimes said that limiting stratal indexation to faithfulness doesn't amount to much since most phonological effects result form interaction of markedness with faithfulness. The justification of this criticism is in a sense proportional to the power of the faithfulness component--in the extreme case, in a model of OT where faithfulness is as fine-grained as markedness, with IDENT[+F] and IDENT[-F] for every imaginable property F it is indeed fully justified. But such models of OT stumble over their own feet for other reasons--a version of OT that reflects markedness in a shadow world of faithfulness constraints is redundant and problematic, a fall-back to rule-based phonology with its structural descriptions ("markedness") and associated structural changes ("faithfulness"), with "A $\rightarrow \mathrm{B} / \mathrm{C} \_\mathrm{D}$ " translated as "[M] * $\mathrm{CAD} »[\mathrm{~F}] *(\mathrm{~A} \rightarrow \mathrm{B})$ ".

In a theory with general and highly symmetric faithfulness constraints confronting highly diversified markedness constraints, one faithfulness constraint impinges on many markedness constraints (not just on "its associated M"). Here limiting indexation to faithfulness constraints is a genuine restriction since severely limits the set of possible strata in a grammar. Theories with unconstrained faithfulness components, on the other hand, lead to the proliferation of stratal distinctions and are overly powerful on general grounds.

\subsection{Loanword adaptation and perceptual assimilation}

This paper has so far been concerned with questions regarding the formal theory of grammar: How does the computational system of an OT-grammar interact with a nonhomogeneous lexicon? Loan adaptation provided interesting data for the investigation of 
this question. We will now consider some issues concerning the relation between the architecture of a (relatively) stable synchronic system of lexicon+grammar, and the diverse factors involved in loanword adaptation. There has been a recent upsurge of work with a somewhat different focus that is concerned with the close empirical observation of concrete loanword adaptation processes. These kinds of investigations (see Dupoux, Kakehi, Hirose, Pallier and Mehler 1999, Jacobs and Gussenhoven 2000, Kang 2003, Kenstowicz 2003, 2004, Paradis 1995, Paradis and LaCharité 1997, Peperkamp and Dupoux 2003, Silverman 1992, Smith 2006, to appear, Yip 1993, 2002, among others) are of interest here for what they can tell us about the phonological component of the grammar and its relation to the perceptual system. This literature presents a wide variety of competing claims, from perception-only approaches to phonology-only approaches, with various intermediate positions.

Of particular interest is a recent proposal developed by Peperkamp and Dupoux (2003) which regards all loanword adaptation as perception-based. Consider a typical case of loanword adaptation in Japanese, in particular, what has traditionally been analyzed as phonological epenthesis to break up illicit clusters and avoid illicit codas. A well-known case often cited in introductory linguistics textbooks is the disyllabic English word Christmas becoming pentasyllabic in the loanword [.k‥ri.su.ma.su.] in Japanese.

The perception-only approach claims that Japanese speakers literally hear three epenthetic vowels in Christmas--(i) by mapping the acoustic input to a representation in terms of available native phonetic categories, which do not include [kr], [sm], and [s\#] and instead substitute [kur], [sum], and [su\#], and (ii) by subsequently mapping this percept to a full-fledged UR, with all epenthetic vowels already in place. Under this view, 
there is no phonological process of epenthesis involved, the grammar needs no separate stratum for loanwords, and no separate faithfulness constraints regulating the foreign stratum in the phonology--it's all in the ears of the beholder, so to speak.

It turns out, however, that this claim is not supported by the available evidence. It has long been known that native speakers' first language molds not only their production, but also their perception of unfamiliar sounds and sound combinations in other languages (in the foundational work in modern phonology, Trubetzkoy (1939:47-50) already presents a detailed and insightful analysis of relevant examples). In recent psycholinguistic work, this has come to be known as "perceptual assimilation" (see Best, McRoberts and Goodell 2001 and work cited there). Speakers of Japanese are no exception. For example, Japanese phonotactics does not admit VCCV sequences like abza (with a first $\mathrm{C}$ not a nasal place-assimilated to the second C), whereas French phonotactics does. Both languages admit VC[u]CV sequences like $a b[u] z a$. Dupoux, Kakehi, Hirose, Pallier and Mehler 1999) have shown that Japanese listeners do much worse than French listeners in discriminating between VCCV stimuli and VC[u]CV stimuli. But it is a far cry from this fact to the idea in Peperkamp and Dupoux 2003 that the epenthetic vowels in a word like [kurisumasu] are literally part of the percept when hearing Christmas, and become automatically part of the UR of the corresponding loanword.

First, if epenthetic vowels were perceptually given and hence indistinguishable from non-epenthetic vowels for speakers of Japanese, there would be no way they could be treated differently by the phonology for some purpose. However, they are treated differently in accent assignment, where we see clear evidence for the operation of a 
constraint of the HEADDEP variety (Alderete 1995, 1999) militating against accent falling on vowels without a correspondent in the source word (see Katayama 1995, 1998, and Kubozono 1996; their findings have been further confirmed in Shinohara 2000 with loan experiments on the basis of French inputs; see also Kenstowicz 2003 for discussion).

Secondly, if the loanword epenthesis were purely perceptual, it should be inescapable as a repair for illicit codas in source words. Smith (2006, to appear) shows that this is by no means the case, adducing deletion/epenthesis doublets like [risurin] 'glycerine' next to epenthesizing [gurisurin], or [ausai] 'outside' next to [autosaido]. She goes on to distinguish between auditory loans and orthographic loans, arguing that it is precisely the deletion versions that constitute perceptual deletions and hence auditory loans, as opposed to the epenthesizing variants, which are orthography-based. Seen in this light, the attempt to anchor the epenthetic vowels of a word like kurisumasu in perception might have the story exactly backwords.

Auditory-orthographic doublets like those cited by Smith 2006 can easily be multiplied. Thus an on-line dictionary ${ }^{5}$ gives two kana transcriptions for the English loanword "good": [guu] and [guddo], with slightly different meanings. [guu] is used as an exclamation ("good!"), whereas [guddo] is found mostly in nativized compounds such as [guddo aidea] 'good idea'. Other common loanword exclamations tend to show deletions (all right $\rightarrow$ [o:rai], don't mind $\rightarrow$ [don mai] 'never mind', encouraging shouts in sports when a team member makes a mistake). For older loans, deletion seems in fact to be the norm. An NHK dialect survey notes a Taisho period (early 20C) loan for 'go ahead'

\footnotetext{
${ }^{5}$ URL: http://www.excite.co.jp/dictionary/japanese/)
} 
[goo hee]. ${ }^{6}$ One of the most interesting linguistic testimonies of the first systematic contacts between speakers of Japanese and Westerners are the so-called Yokohama $k o t o b a,{ }^{7}$ the vocabulary used by 19 th century Yokohama merchants to communicate with their American and European trading partners. Examples appear in (21).

(21) Yokohama kotoba (Kanagawa Prefecture Social Studies Research Council 1996)

\begin{tabular}{l|ll} 
& Yokohama loan & Modern loan \\
(ice) cream & kurin & kuriimu \\
five & fai & faibu \\
eight & ei & eito
\end{tabular}

The Yokohama kotoba in the column on the left should be compared with the current used variants of these loanwords listed on the right. Where we find final epenthesis in the currently used loanword, the Yokohama version of 'cream' contains a final moraic nasal, and the codas for the numbers 'five' and 'eight' are simply deleted.

Why this difference? The syllable structure restrictions have not changed, and neither the perception-only approach nor the grammar-only approach can give a plausible answer. It seems difficult to argue that the perception of 19th century Japanese speakers was radically different from that of 20th century Japanese speakers, in such a way that at some point the latter started hearing epenthetic vowels. In terms of the indexed faithfulness grammar, the difference can certainly be encoded in the relative ranking of

\footnotetext{
${ }^{6}$ URL: http://www.asahi-net.or.jp/ QM4H-IIM/ktb_fr_a.htm

${ }^{7}$ URL: http://www.search-japan.com/honmoku/rekisi/rekisi1.html\#rekisi_7
} 
MAX-segment (constraint against deletion) and DEP-segment (constraint against insertion), but such a change cannot be motivated in any other part of Japanese phonology.

A more illuminating interpretation takes up the idea that at least two different strategies for loanword adaptation are available to speakers: (i) perception loan adaptation, the main strategy of the Yokohama loans, and (ii) phonemic loan adaptation, which became the prevalent loanword strategy in Japanese and are based on a rationalization of English orthography, which diverges from both British and American pronunciation habits in several respects.

The goals of the two types of loanword adaptation are different. The Yokohama kotoba are aimed at communicating with speakers of English, and are therefore as close to the pronunciation of the source word as Japanese syllable structure would allow. But how do we measure closeness? From a segmental perspective, it is not clear which is more faithful to the source word--the deleting version has too few consonants, the epenthesizing version too many vowels. But in fact, the Yokohama loans have a crucial point in their favor: They are more faithful to the English source in their prosodic (syllabic) make-up--the source words five and eight in (21) are monosyllabic, and so are the consonant deletion versions [fai] and [ei]. On the other hand, the phonemic (and orthographic) form of the source word is hard to recover from these items. This, then, is a type of Output-Output prosodic correspondence, reflecting the fact that the 19th century Yokohama kotoba are auditory loans.

The epenthesizing loanwords that populate the current Japanese language are mostly used to communicate with other speakers of Japanese, and they are strongly based on 
spelling, with well-defined strategies for placing the epenthetic vowels so that all source consonants are protected from deletion. There is no attempt to preserve the prosodic structure of the source words (epenthesis almost inevitably changes the number and shape of syllables). Instead, the phonemic (and orthographic) form of the source word is largely recoverable (apart from segmental neutralizations such as $1, r>r$ ).

Overall, there can be no question that the perception-based account is on the right track in certain areas of loanword phonology such as the cases illustrated in (21). The epenthesis strategy seen in the overwhelming number of Japanese loans, however, seems to involve more than just perceptual adaptation. Other areas where perception plays a direct role are not difficult to find. Consider the facts in (22).

$$
\begin{aligned}
& \text { Palatalization of velars before original [æ] } \\
& \text { /_[æ] cf.: /_[ }] \\
& \text { [k'jatto }] \text { 'cat' [katto] 'cut' } \\
& \text { [g gamburu] 'gamble' [gamu] 'gum' }
\end{aligned}
$$

The English front low vowel [æ] triggers a significant degree of allophonic palatalization of preceding velars, which is perceived by speakers of Japanese and preserved in the Japanese loanword. The motivation here is clearly not contrast-based: If the reason for the palatalization was to distinguish 'cat' and 'cut' (kyatto vs. katto), then labials should also follow this pattern. But they do not, as shown in (23). Our interpretation here is that 
palatalization of labials before $[æ]$ is negligible, and hence no perceptual effect is expected in the loanwords.

(23) No palatalization of labials before original [æ]

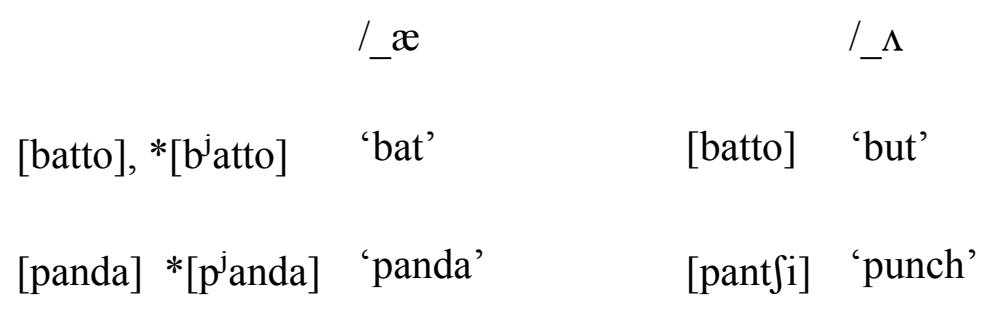

\section{Implications for the general theory}

The stratified grammar developed and argued for in section 2 (repeated here in (24)) identifies the relevant voicing-related markedness constraints and interleaved indexed faithfulness constraints.

(24) Stratified grammar (repeated from (16))

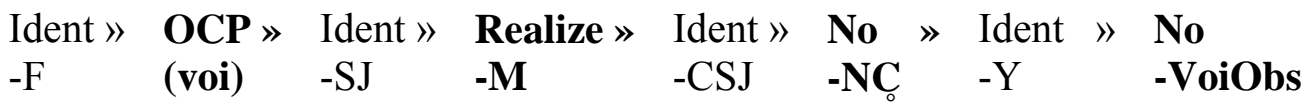

In this (partial) grammar, IDENT-F is ranked highest, ensuring that F-items can surface with violations of the voicing-related markedness constraints, such as OCP(VOI) and NoNC. The ranking in (24) does not exist in a vacuum, however, but is part of the overall 
grammar of Japanese. As is usual in OT, it is always possible for other aspects of the overall constraint system to lead to the selection of a different winner.

Here we take up two cases where new generalizations have emerged that are at first glance problematic for (24), namely, cases where OCP(VOI) and NO-NC appear to be observed in F-items, even though the model with high-ranking IDENT-F predicts otherwise. We will show that the overall model not only successfully deals with these cases, but actually already predicts that they should be possible.

\subsection{TETU I: contextual markedness}

As a theory of ranked and violable constraints, OT makes a clear prediction: IDENT-F, even though highest ranked so far, can still be trumped by an even higher ranking markedness constraint, which would manifest itself in a kind of Emergence-of-theUnmarked effect (TETU, see McCarthy and Prince 1995) in the foreign stratum. A case in point is the novel finding by Nishimura 2001) regarding the constraint against voiced geminates (a constraint never violated in $\mathrm{Y}$ - and SJ-items). Starting with the observation in Ito and Mester 1995a, 1999 that this constraint is also responsible for the devoicing of geminates found in some assimilated F-items (such as bakku 'bag' and betto 'bed'), Nishimura surveyed recent loanword patterns through Google searches and found that geminate devoicing is especially frequent in one specific type of loanwords: those containing a second voiced obstruent besides the geminate voiced obstruent. This is schematically illustrated by the contrast shown in (25). 
This finding is surprising because $\mathrm{OCP}(\mathrm{VOI})$ should be inactive on such F-items, given the ranking IDENT-F » $\mathrm{OCP}(\mathrm{VOI})$. The tendency to devoice in the context of additional obstruent voicing is confirmed in (26), which replicates Nishimura's search at a later date.

(26) Google hits on 7/23/05, 11:40am EST

\begin{tabular}{l|l|l|l} 
& & $\#$ of hits & $\%$ \\
\hline voiced & hotto doggu & 129000 & $68 \%$ \\
\hline devoiced & hotto dokku & 62000 & $32 \%$
\end{tabular}

\begin{tabular}{l|l|l|l} 
& & $\#$ of hits & $\%$ \\
\hline voiced & hamu eggu & 27100 & $99.9 \%$ \\
\hline devoiced & hamu ekku & 25 & $0.1 \%$
\end{tabular}

In order to capture these facts, Nishimura (2001) proposes a contextual markedness constraint against voiced obstruent geminates in co-occurrence with another voiced obstruent. ${ }^{9}$ This constraint, variably ranked with respect to IDENT-F, can force a violation of the latter and map /doggu/ to [dokku], with a devoicing geminate (and without an

\footnotetext{
${ }^{8}$ A familiar example is burudokku tonkatu soosu ${ }^{\mathrm{TM}}$ 'Bulldog tonkatsu sauce'.

${ }^{9}$ See also Kawahara 2005 for an intereasting faithfulness-based restatement of Nishimura's original observation.
} 
OCP(VOI) violation). The result shows that even highly ranked indexed faithfulness can be trumped by a contextual version of a lower-ranking markedness constraint.

\subsection{TETU II: Allomorphy and faithfulness neutralization}

A second kind TETU effect occurs in situations where faithfulness, instead of being trumped by markedness, is neutralized in some other way. The result is that dominated markedness, otherwise muted, suddenly becomes decisive.

A case in point is an interesting generalization first noted by Tateishi $(2001,2003)$ concerning the ways in which the English plural s-suffix appears in loanwords. Japanese does not have a regular plural marker, and English words that are usually pluralized are sometimes borrowed with the plural marker intact (doonattsu 'donuts', piinattsu 'peanuts'), a cross-linguistically common event (Campbell 1999:57-88), sometimes without (surippaa 'slippers', koon fureeku 'corn flakes'); in still other cases both pluralized and non-pluralized forms are found (27). As a result, loanword Japanese has come to possess a quasi-suffix expressing some kind of plurality.

\begin{tabular}{l|l|l|l} 
With plural suffix & & without plural suffix & \\
\hline$[$ kyattsu $]$ & 'Cats' (title of musical) & [kyatto fuudo $]$ & 'cat food' \\
\hline [handzu appu $]$ & 'hands up' & [hando kuriimu $]$ & 'hand cream'
\end{tabular}


Loanwords with $-\mathrm{su} / \mathrm{zu}$, with the expected epenthesis, are found among the growing Fitems. Tateishi $(2001,2003)$ noted that the distribution of the two variants in the loanwords does not necessarily follow the distribution of the corresponding English elements, i.e., voiced after voiced, and voiceless after voiceless. In particular, the voiceless variant is sometimes found in unexpected environments:

English source word Japanese loan word

men's $[\mathrm{z}] \quad$ menzu $\sim$ *mensu

ladies $[\mathrm{z}] \quad$ lediisu $\sim$ lediizu

The results of a Google search for co-occurrences of the different versions, in katakana syllabary, of "men's/ladies" and "dragons/tigers" (names of baseball teams) appear in (29) and (30).

(29) "men's, ladies"-- Google Search (July 23, 2005, 2:18pm EST)

men-zu, redii-su $\quad 1,870,000 \quad 99.6701 \%$

men-zu, redii-zu $\quad 5,570 \quad 0.2969 \%$

men-su, redii-su $611 \quad 0.0326 \%$

men-su, redii-zu $8 \quad 0.0004 \%$ 
(30) "dragons, tigers" Google Search (July 23, 2005, 2:35pm EST)

\begin{tabular}{lll} 
doragon-zu, taigaa-su & 48,600 & $97.6335 \%$ \\
\hline doragon-zu, taigaa-zu & 807 & $1.6212 \%$ \\
doragon-su, taigaa-su & 361 & $0.7252 \%$ \\
doragon-su, taigaa-zu & 10 & $0.0201 \%$
\end{tabular}

Here [-zu] occurs after nasal-final loanwords, and [-su] elsewhere--quite different from the allophonic rule in English. The generalization is not without exceptions, but apparently solid enough to warrant a systematic explanation. Even though divergent from what is found in English, it might still reflect some phonetic property of the English models, similar to the way final vowel epenthesis in plosive-final English loans in Korean appears to correlate with the probability that the corresponding plosive is released in American English (see Kang 2003). In the present case, however, this mode of explanation seems less attractive: We are not aware of relevant empirical studies, but the idea that the postnasal -[z] of dragons should be consistently more strongly voiced than the postvocalic -[z] of tigers seems farfetched.

Setting aside the possibility of explaining the distribution as learned through diligent observation of American English pronunciation habits, we turn to another attractive mode of explanation--the constraints of universal phonology, as ranked in the grammar of Japanese. The -su/zu pattern obviously conforms to the postnasal voicing pattern familiar from the native stratum of Japanese (see (8)-(10) above). This suggests, 
and all recent analyses (Tateishi 2001, 2003, Fukazawa, Kitahara and Ota 2002, and the one developed here ${ }^{10}$ ) agree on this point, that what we are dealing with is an F-item on which No-NÇ is in some way active. But in what way? This is where our hypothesis departs from the other two, who see this as a case of restratification, arguing that the foreign quasi-suffix has either joined the Y-items (Tateishi 2003) or is subject to lowerranking affixal IDENT (Fukazawa, Kitahara and Ota 2002). Either way, the IDENT responsible for /-su/ ranks below No-NC. . These are certainly viable analyses, but there is some concern whether it is really correct to declare -su/zu a native suffix (in the face of speakers' intuitions declaring it to be distinctly 'foreign'), and in general a proliferation of faithfulness constraints dealing with single elements should give us pause.

Is there a simpler alternative? Our claim is that there is: In English, the s-plural morpheme is realized as voiced or voiceless, depending on the environment. The crucial voiced/voiceless distinctions in the phonological environment are lost in Japanese because of epenthesis: (Boston) Pop[s] $\rightarrow$ poppusu, (Chicago) $\mathrm{Cub}[\mathrm{z}] \rightarrow$ kabusu. As a result, both allomorphs are borrowed as a lexically listed pair/-su, -zu/. But once this is the case, the ranking [IDENT-F » ...» NO-NÇ » IDENT-Y » NO-VOIOBS], already firmly anchored in the grammar (see (24)), predicts the distribution that Tateishi discovered. Allomorph listing means that allomorph selection is purely phonologically conditioned. With faithfulness (i.e., IDENT-F) neutralized, as far as voicing is concerned, the subhierarchy [NO-NC » IDENT-Y » NO-VOIOBS] means voiced after nasals (doragon-zu, (31)), otherwise voiceless (taigaa-su (32)).

\footnotetext{
${ }^{10}$ First presented in class lectures at the 2005 LSA Linguistic Institute at MIT/Harvard University (JulyAugust 2005).
} 


\begin{tabular}{|c|l|l|l|l|}
\hline$/$ doragon/, /-zu, -su/ & Ident-F & No-NC & Ident & No-VoiObs \\
\hline doragon zu & & & & $\left(*^{*} *_{\mathrm{g}}\right) *^{*}$ \\
\hline doragon su & & $* !$ & & $\left(*^{\mathrm{d}} *_{\mathrm{g}}\right)$ \\
\hline
\end{tabular}

\begin{tabular}{|c|l|l|l|l|}
\hline /taigaa/, /-zu, -su/ & Ident-F & No-NC & Ident & No-VoiObs \\
\hline taigaa zu & & & & $\left({ }^{*} \mathrm{~g}\right){ }^{*} \mathrm{z} !$ \\
\hline taigaa su & & & & $\left({ }^{*} \mathrm{~g}\right)$ \\
\hline
\end{tabular}

Exceptions are cases of straight borrowing of voiced [-zu], such as syuu-zu 'shoes'. This avoids both construction-specific rules and unenlightening listing of allomorph environments and follows the OT analysis of allomorphy and lexical selection in many earlier studies, beginning with Mester 1994 for Latin (see Anttila 1997, Burzio 1994, 1997, Kager 1996, Mascaró 1996a, 1996b, Perlmutter 1998, Russell 1995, Tranel 1996a, 1996b, 1998, among others). This leads to a TETU-effect for such listed pairs of allomorphs (Mascaró 1996b)--here, postnasal voicing in tandem with default voicelessness--in thoroughly foreign territory, where IDENT-F otherwise prevents any changes in voicing. Similar TETU-effects with affixal elements in Japanese arise with Sino-Japanese counters (Ito and Mester 2003:138-141) and verbal suffixes (Ito and Mester 2004). 
Overall, taking on phonological processes in their actual lexical complexity, including the patterning and lexical distribution of the various kinds of underapplication and overapplication, is a fruitful enterprise. It leads to a deeper understanding of the way phonology, as a computational system of ranked constraints, interacts with the lexicon. This interaction is mediated through indexed faithfulness constraints, which provides the phonology with the means to fold the non-uniformities of a historically grown stratified lexicon into a single coherent synchronic system. The architecture of OT allows us to understand why peripheral items like loanwords can be both more marked than native words in some respects, and less marked in others (TETU-effects). Far from being a problem for the theory, these are in fact points in its favor in that new generalizations are found that would otherwise not have been discovered.

\section{References}

Alderete, John. 1995. Faithfulness to prosodic heads. Ms. Amherst, MA: University of Massachusetts at Amherst. Rutgers Optimality Archive 94-0000. http://roa.rutgers.edu/view.php3?id=514.

Alderete, John. 1999. Head dependence in stress-epenthesis interaction. In The derivational residue in phonological Optimality Theory, eds. Ben Hermans and Marc van Oostendorp, 29-50. Amsterdam: John Benjamins.

Anttila, Arto. 1997. Deriving variation from grammar. In Variation, Change, andPhonological Theory, eds. Frans Hinskens, Roeland van Hout and W. Leo Wetzels, 35-68. Amsterdam: Benjamins. 
Anttila, Arto, and Young-Mee Yu Cho. 1998. Variation and change in optimality theory. Lingua 104:31-56.

Anttila, Arto. 2002. Morphologically conditioned phonological alternations. Natural Language and Linguistic Theory 20:1-42.

Best, Catherine T., Gerald W. McRoberts, and Elizabeth Goodell. 2001. Discrimination of non-native consonant contrasts varying in perceptual assimilation to the listener's native phonological system. The Journal of the Acoustical Society of America 109:775-794.

Burzio, Luigi. 1994. Principles of English Stress. Cambridge, U.K.: Cambridge University Press.

Burzio, Luigi. 1997. Cycles, non-derived-environment blocking, and correspondence. Ms.: Johns Hopkins University.

Campbell, Lyle. 1999. Historical Linguistics: An Introduction. Cambridge, MA: MIT Press.

Chomsky, Noam, and Morris Halle. 1968. The Sound Pattern of English. New York: Harper \& Row.

Dupoux, Emmanuel, Kazuhiko Kakehi, Yuki Hirose, Christophe Pallier, and Jacques Mehler. 1999. Epenthetic vowels in Japanese: A perceptual illusion? Journal of Experimental Psychology: Human Perception and Performance 25:1568-1578.

Fukazawa, Haruka. 1998. Multiple input-output faithfulness relations in Japanese. Ms.: University of Maryland, College Park. ROA-260-0698.

Fukazawa, Haruka, Mafuyu Kitahara, and Mitsuhiko Ota. 2002. Constraint-Based Modelling of Split Phonological Systems. Phonological Studies 5:115-120. 
Inkelas, Sharon, Orhan Orgun, and Cheryl Zoll. 1997. The implications of lexical exceptions for the nature of grammar. In Derivations and Constraints in Phonology, ed. Iggy Roca, 393-418. Oxford: Oxford University Press.

Ito, Junko, and Armin Mester. 1986. The phonology of voicing in Japanese: Theoretical consequences for morphological accessibility. Linguistic Inquiry 17:49-73.

Ito, Junko, and Armin Mester. 1995a. The core-periphery structure of the lexicon and constraints on reranking. In Papers in Optimality Theory, eds. Jill Beckman, Suzanne Urbanczyk and Laura Walsh, 181-210. Amherst: GLSA.

Ito, Junko, and Armin Mester. 1995b. Japanese phonology. In Handbook of Phonological Theory, ed. John Goldsmith, 817-838. Cambridge, MA: Blackwell.

Ito, Junko, and Armin Mester. 1999. The phonological lexicon. In A Handbook of Japanese Linguistics, ed. Natsuko Tsujimura, 62-100. Oxford: Blackwell.

Ito, Junko, and Armin Mester. 2003. Japanese Morphophonemics: Markedness and Word Structure. Linguistic Inquiry Monographs, 41. Cambridge, MA, and London, England: MIT Press.

Ito, Junko, and Armin Mester. 2004. Morphological contrast and merger: ranuki in Japanese. Journal of Japanese Linguistics 20:1-18.

Jacobs, Haike, and Carlos Gussenhoven. 2000. Loan phonology: Perception, salience, the lexicon, and OT. In Optimality Theory: Phonology, Syntax, and Acquisition, eds. Jost Dekkers, Frank van der Leeuw and Jeroen van de Weijer, 193-209. Oxford: Oxford University Press.

Kager, René. 1996. On Affix Allomorphy and Syllable Counting. Ms. ROA-88. 
Kanagawa Prefecture Social Studies Research Council. 1996. Kanagawa-ken-no rekishisampo [History walks through Kanagawa Prefecture]. Rekishisampo 14. Tokyo: Yamakawa Publishing.

Kang, Yoonjung. 2003. Perceptual similarity in loanword adaptation: English postvocalic word-final stops in Korean. Phonology 20:219-273.

Katayama, Motoko. 1995. Loanword accent and minimal reranking in Japanese. In Phonology at Santa Cruz: Papers on Stress, Accent, and Alignment, eds. Rachel Walker, Ove Lorentz and Haruo Kubozono, 1-12: Linguistics Research Center, UC Santa Cruz.

Katayama, Motoko. 1998. Optimality Theory and Japanese Loanword Phonology, Department of Linguistics, University of California, Santa Cruz: Doctoral Dissertation.

Kawahara, Shigeto, Kohei Nishimura, and Hajime Ono. 2003. Unveiling the Unmarkedness of Sino-Japanese. In Japanese/Korean Linguistics 12, ed. William McLure, 140-151. Stanford: CSLI Publications.

Kawahara, Shigeto. 2005. A faithfulness ranking projected from a perceptibility scale: the case of [+voice] in Japanese. Ms. ROA 749-0605.

Kenstowicz, Michael. 2003. Salience and similarity in loanword adaptation: A case study from Fijian. Ms. ROA-609. Cambridge, MA: MIT.

Kenstowicz, Michael. 2004. Issues in loanword phonology. Ms. Paper presented at a Phonetic Society of Japan workshop; Tokyo University of Foreign Studies; December 13. Cambridge, MA. 
Kubozono, Haruo. 1996. Syllable and accent in Japanese: evidence from loanword accentuation. Bulletin of the Phonetic Society of Japan 211:71-82.

Mascaró, Joan. 1996a. External Allomorphy and Contraction in Romance. Probus 8:181205.

Mascaró, Joan. 1996b. External Allomorphy as Emergence of the Unmarked. In Current Trends in Phonology: Models and Methods, eds. Jacques Durand and Bernard Laks. University of Salford, Manchester: European Studies Research Institute.

McCarthy, John J., and Alan S. Prince. 1995. Faithfulness and Reduplicative Identity. In University of Massachusetts Occasional Papers in Linguistics UMOP 18, eds. Jill Beckman, Suzanne Urbanczyk and Laura Walsh, 249-384. Amherst, MA: GLSA.

McCarthy, John J., and Alan S. Prince. 1999. Faithfulness and identity in prosodic morphology. In The Prosody-Morphology Interface, ed. Harry van der Hulst René Kager, and Wim Zonneveld, 218-309. Cambridge, U.K.: Cambridge University Press.

McCawley, James D. 1968. The Phonological Component of a Grammar of Japanese. The Hague, The Netherlands: Mouton.

Mester, Armin. 1994. The quantitative trochee in Latin. Natural Language and Linguistic Theory 12:1-61.

Nishimura, Kohei. 2001. Lyman's Law in Japanese Loanwords. Ms.

Orgun, Orhan. 1996. Sign-based Morphology and Phonology, with special attention to Optimality Theory, University of California, Berkeley: Doctoral dissertation. 
Paradis, Carole. 1995. Derivational constraints in phonology: Evidence from loanwords and implications. In CLS 31, eds. Audra Dainora, Rachel Hemphill, Barbara Luka, Barbara Need and Sheri Pargman, 360-374. Chicago: CLS.

Paradis, Carole, and Darlene LaCharité. 1997. Preservation and minimality in loanword adaptation. Journal of Linguistics 33:379-430.

Pater, Joe. 2000. Nonuniformity in English secondary stress: the role of ranked and lexically specific constraints. Phonology 17:237-274.

Pater, Joe. 2005. The locus of exceptionality: morpheme-specific phonology as constraint indexation. Ms. Amherst, MA: University of Massachusetts, Amherst.

Peperkamp, Sharon, and Emmanuel Dupoux. 2003. Reinterpreting loanword adaptations: the role of perception. Proceedings of the 15th International Congress of Phonetic Sciences. 367-370.

Perlmutter, David M. 1998. Interfaces: Explanation of Allomorphy and the Architecture of Grammars. In Morphology and Its Relation to Phonology and Syntax, eds. Steven G. Lapointe, Diane K. Brentari and Patrick M. Farrell, 307-338. Stanford, CA: CSLI Publications.

Pierrehumbert, Janet. 2006. The statistical basis of an unnatural alternation. In Laboratory Phonology 8, eds. Louis Goldstein, Douglas H. Whalen and Catherine T. Best. The Hague: Mouton de Gruyter, 81-106.

Russell, Kevin. 1995. Morphemes and candidates in Optimality Theory. Ms.: University of Manitoba. ROA-44.

Silverman, Daniel. 1992. Multiple scansions in loanword phonology: Evidence from Cantonese. Phonology 9:289-328. 
Smith, Jennifer L. 2006. Loanword adaptation is not all perception: Evidence from Japanese loan doublets. In Japanese/Korean Linguistics 14, eds. Timothy J. Vance \& Kimberly A. Jones. Stanford: CSLI, 63-74.

Smith, Jennifer L. to appear. Source similarity in loanword adaptation: Correspoindence Theory and the posited source-language representation. In Phonological Argumentation: Essays on Evidence and Motivation, ed. Steve Parker. London: Equinox.

Tateishi, Koichi. 2003. Phonological Patterns and Lexical Strata. Ms. Paper presented at CIL XVII, July 24-29, 2003, Prague.

Tateishi, Koichi. 2001. On'in jisho kurasu seeyaku no bunpu ni tsuite [on the distribution of constraints for phonological sub-lexica]. Ms. Paper presented at the 26th meeting of the Kansai Linguistic Society Ryukoku University, Kyoto.

Tranel, Bernard. 1996a. French Liaison and Elision Revisited: A Unified Account within Optimality Theory. In Aspects of Romance Linguistics, eds. Claudia Parodi, Carlos Quicoli, Mario Saltarelli and María-Luisa Zubizarreta, 433-455. Washington, D.C.: Georgetown University Press.

Tranel, Bernard. 1996b. Exceptionality in Optimality Theory and Final Consonants in French. In Grammatical Theory and Romance Languages, ed. Karen Zagona, 275-291. Amsterdam \& Philadelphia: John Benjamins.

Tranel, Bernard. 1998. Suppletion and OT: on the issue of the syntax/phonology interaction. In Proceedings of the West Coast Conference on Formal Linguistics 16, eds. Emily Curtis, James Lyle and Gabriel Webster, 415-429. 
Trubetzkoy, Nikolai Sergeevich. 1939. Grundzüge der Phonologie. Traveaux du Cercle Linguistique de Prague 7. [Reprinted by Vandenhoeck and Ruprecht, Göttingen, 1967.].

Yip, Moira. 1993. Cantonese loanword phonology and Optimality Theory. Journal of East Asian Linguistics 2:261-292.

Yip, Moira. 2002. Perceptual influences in Cantonese loanword phonology. Journal of the Phonetic Society of Japan 6:4-21. 